\title{
Congenital diffuse infiltrating lipomatosis of face in a newborn
}

\author{
Pareshkumar Amrutlal Thakkar ${ }^{1}$, Ashutosh Singh Rathore ${ }^{2}$
}

Sri Lanka Journal of Child Health, 2015; 44(1): 61-63

(Key words: neonate; lipoma; infiltrating lipomatosis; congenital)

\section{Case report}

A full term appropriate for date, male neonate, born of a non-consanguineous marriage to a $2^{\text {nd }}$ gravida mother, had a diffuse swelling on right cheek (Figure 1).

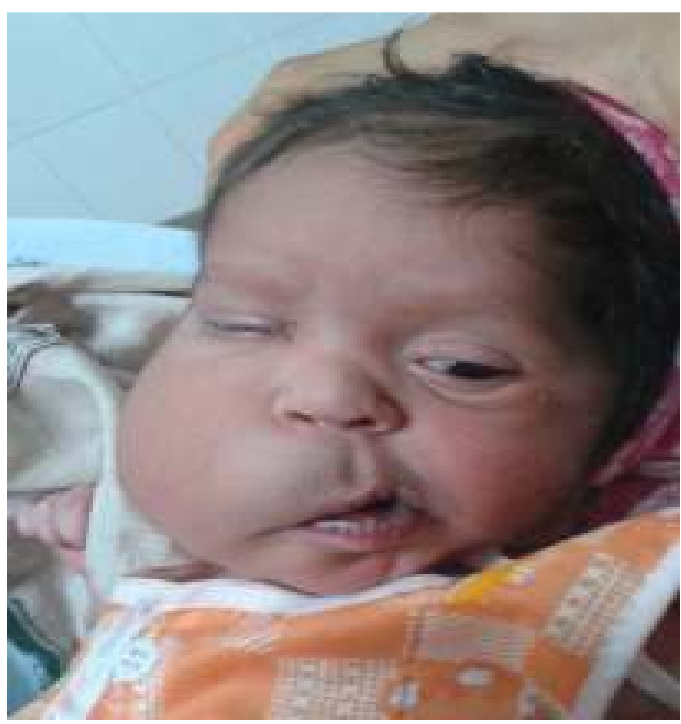

Figure 1: Diffuse swelling of right cheek

There were no perinatal complications. Mother did not have any major illness in the past or during the pregnancy. There was no history of exposure to teratogens during pregnancy. The baby was delivered by caesarean section done for cephalopelvic disproportion on $11^{\text {th }}$ July, 2012 at SSG Hospital, Vadodara.

On examination, the baby had a single, large, soft, ill defined, non tender, non cystic, swelling on the right aspect of the face extending from midline to whole of the right face and encroaching on the right ear. This swelling did not cause any difficulty in breast feeding.

Ultrasonography of the local part showed diffuse

${ }^{1}$ Associate Professor, ${ }^{2}$ Postgraduate Student, Department of Pediatrics, Medical College and SSG Hospital, Baroda, India

(Received on 12 December 2013: Accepted after revision on 24 January 2014) proliferation of subcutaneous fat (Hypoechoic fat with echogenic strands, without a well-defined capsule, without calcification and without hypervascularity). Magnetic resonance imaging (MRI) of right cheek - plain and contrast, done using T1, T2, SPIR axial, FLAIR axial, T1 \& T2 coronal \& T2 sagittal sequences with post contrast $\mathrm{T} 1$ sequence, was hyperintense in $\mathrm{T} 1$, hypointense in $\mathrm{T} 2$ and hypointense in fat saturated image scans i.e. focal non enhancing thickening of subcutaneous tissue and its fat in right cheek suggestive of lipoma (Figure 2).

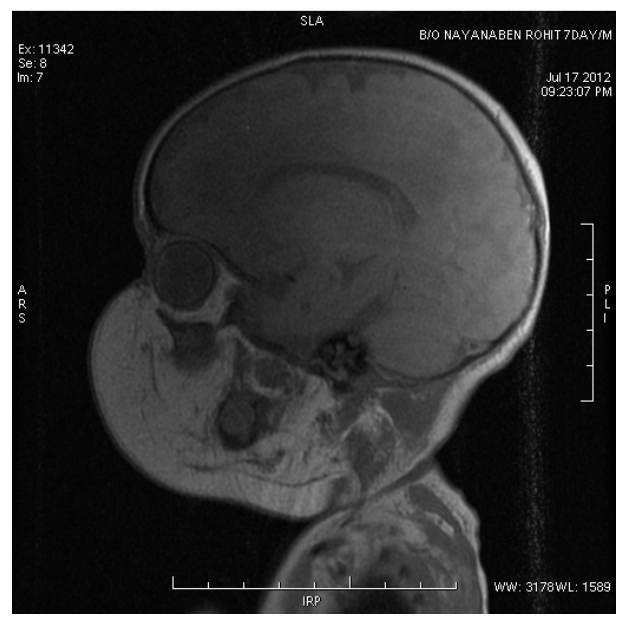

Figure 2a: MRI sagittal view

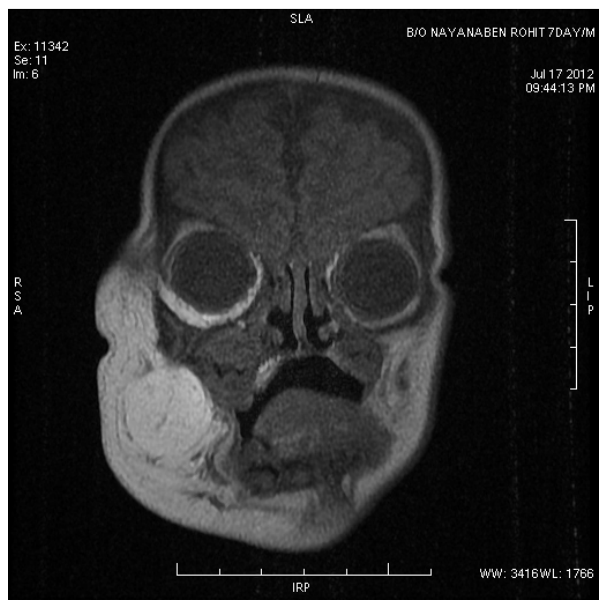

Figure 2b: MRI coronal view 
Parents were counselled regarding the therapeutic options available. They were told that the purpose of the surgery is cosmetic, that there is a high rate of recurrence, that it may not be possible to remove the tumour completely and that there is no risk of transformation to malignancy. The parents decided to wait for surgery and child is being regularly followed up.

\section{Discussion}

Benign lipomas are classified into five subgroups: a) simple encapsulated lipoma b) lipoma variants such as angiolipoma c) hamartomatous lesions d) infiltrating or diffuse lipomatosis and e) benign tumour of brown fat, i.e., hibernoma ${ }^{1}$. Infiltrating lipomas usually occur after the third decade of life and involve subcutaneous tissue, muscle and bone ${ }^{1}$. When they have been present since birth or infancy they are called congenital infiltrating lipomatosis and are commonly seen in the face ${ }^{2}$. Congenital infiltrating lipomatosis of the face (CIL-F) is a distinct clinico-pathological rare entity, first described by Slavin et al. in $1983^{3}$. Since then several case reports have been reported in the literature ${ }^{1,4,5,6,7}$

Pathologically, congenital infiltrating lipomas show the following characteristics: a) they are nonencapsulated congenital fatty tumours b) they infiltrate adjacent muscles and soft tissues c) there is absence of lipoblasts and malignant characteristics d) fibrous elements are present and e) there is hypertrophy of subjacent bone ${ }^{8}$.

CIL-F can be diagnosed based on clinical and imaging features. Plain $\mathrm{x}$-rays show facial bone hypertrophy and soft tissue swelling ${ }^{2}$. Ultrasonography may show adipose tissue but cannot delineate the extent of the lesion ${ }^{2}$. Computed tomography (CT) scan and MRI are the most helpful tools for preoperative radiographic evaluation as they can identify the fat content of the lesions and delineate their extent ${ }^{9}$. CT scan shows fat-density lesions in great detail. Intervening fibrous elements can give a feathery pattern or nonhomogeneous character $^{1,9}$. MRI is superior to CT and can depict the exact extent of the lesion ${ }^{9}$. The lesions are non-homogeneously hyperintense on T1W images. Muscle and bony involvement are better seen with $\mathrm{MRI}^{9}$. Biopsy may not be required if the typical findings are seen on $\mathrm{MRI}^{2}$.

Recurrence rate of infiltrating lipomatosis was estimated to be between $27.3 \% \& 62.5 \%{ }^{10,11,12}$. It is not always possible to completely remove the facial lesions involving indispensable structures. The main purpose of surgery is to improve the aesthetic look rather than to eradicate the tumour. In order to preserve the important structures and to obtain satisfactory aesthetic results some surgeons have managed these diseases with superficial parotidectomy and extensive facial nerve dissection $^{2,8}$. Aggressive surgical resection or liposuction is not the ideal treatment for CIL-F since there are no documented cases of infiltrating lipomatosis in the current literature degenerating into frank malignancy ${ }^{10}$.

In summary, CIL-F is a very rare disease in infancy or childhood characterized by congenital origin, diffuse infiltration of mature adipose tissue over normal muscle fibres, rapid growth, associated osseous hyperplasia (not evident in our case) and high recurrence rate after surgical intervention. The clinical presentation, CT and MRI help accurate diagnosis before surgical treatment planning. The main purpose of surgery is to improve the cosmetic appearance rather than to eradicate the tumour.

\section{References}

1. Chen CM, Lo LJ, Wong HF. Congenital infiltrating lipomatosis of the face: Case report and literature review. Chang Gung Medical Journal 2002; 25(2):194-200.

2. Heymans O, Ronsmans C. Congenital infiltrating lipomatosis of the face. European Journal of Plastic Surgery 2005; 28:186-9. http://dx.doi.org/10.1007/s00238-005-0739-x

3. Slavin SA, Baker DC, McCarthy JG, Mufarrij A, Congenital infiltrating lipomatosis of the face: clinico-pathologic evaluation and treatment. Plastic and Reconstructive Surgery 1983; 72(2): 158-64.

http://dx.doi.org/10.1007/s00238-005-0739-x

4. de Rosa G, Cozzolino A, Guarino M, C. Giardino C. Congenital infiltrating lipomatosis of the face: report of cases and review of the literature. Journal of Oral and Maxillofacial Surgery 1987; 45 (10): 879-83. http://dx.doi.org/10.1016/02782391(87)90240$\underline{0}$

5. Rajeswaran R, Murthy J, Chandrasekharan A, Joseph S. Case report: congenital infiltrating lipomatosis of face. Indian Journal of Radiology and Imaging 2008; 18(4): 306-9. http://dx.doi.org/10.4103/0971-3026.43847

6. Kamal D, Breton P, Bouletreau P. Congenital infiltrating lipomatosis of the face: report of three cases and review of the literature, Journal of Cranio-Maxillofacial Surgery 2010; 38(8): 610-14. http://dx.doi.org/10.1016/j.jcms.2010.02.014 
7. Singh K, Sen P, Musgrove BT, Thakker N, Facial infiltrating lipomatosis: a case report and review of literature. International Journal of Surgery Case Reports 2011; 2(7): 201-5. http://dx.doi.org/10.1016/j.ijscr.2011.06.007

8. Coffin CM. Adipose and myxoid tumours: A clinical, pathological and therapeutic approach. Paediatric Soft Tissue Tumours: Baltimore: Williams \& Wilkins Co; 1997.254

9. Salvatore C, Antonio B, Del Vecchio W, Lanza A, Tartaro G, Giuseppe C. Giant infiltrating lipoma of the face: CT and MR imaging findings. American Journal of Neuroradiology 2003; 24:283-6.

10. Enzinger FM, Weiss SW. Benign lipomatous tumours. In: Enzinger FM, Weiss SW, editors. Soft tissue tumours. 3rd ed. St Louis: Mosby; 1995.p.381-430.
11. Scherl MP, Som PM, Biller HF, Shah K. Recurrent infiltrating lipoma of the head and neck: Case report and literature review. Archives of Otolaryngology- Head \& Neck Surgery 1986; 112:1210-2.

http://dx.doi.org/10.1001/archotol.1986.03780 110086014

12. Lasso, J.M, Espa na A, Alava D, Bazán A. Congenital infiltrating lipoma of the upper limb in a patient with von Willebrand disease. British Journal of Dermatology 2000; 143:180-2.

http://dx.doi.org/10.1001/archotol.1986.03780 110086014 